\title{
Prognostic significance of mammalian sterile20-like kinase 1 in colorectal cancer
}

\author{
Parham Minoo $^{1}$, Inti Zlobec ${ }^{1}$, Kristi Baker ${ }^{1}$, Luigi Tornillo², Luigi Terracciano ${ }^{2}$, \\ Jeremy R Jass ${ }^{1}$ and Alessandro Lugli ${ }^{1,2}$ \\ ${ }^{1}$ Department of Pathology, McGill University, Montreal, QC, Canada and ${ }^{2}$ Institute of Pathology, University \\ Hospital of Basel, Basel, Switzerland
}

\begin{abstract}
Mammalian Sterile20-like kinase 1 (Mst1) is a member of the yeast Ste20-related kinase family known to be involved in the process of apoptosis initiated by a variety of stimuli. The aim of this study was to determine the prognostic significance of Mst1 expression in colorectal cancer. A series of 1197 mismatch-repair-proficient colorectal cancers retrieved from a tissue microarray were randomized into two study groups. On the first group $(n=599)$ receiver operating characteristic curves were used to determine the most clinically useful cutoffs to describe Mst1 expression with respect to $\mathrm{T}$ stage, $\mathrm{N}$ stage, tumor grade, vascular invasion and overall survival. The association of Mst1 expression and each outcome was immunohistochemically evaluated on the second study group $(n=598)$ as well as on a third study group comprising 141 mismatch-repair-deficient colorectal cancers. A univariate analysis in the second study group showed that loss of cytoplasmic Mst1 was associated with higher $T$ stage $(P=0.001)$, higher $N$ stage $(P=0.029)$, vascular invasion $(P=0.017)$ and overall survival $(P=0.014)$. Nuclear Mst1 expression was not significantly associated with $N$ stage, $T$ stage or vascular invasion but was associated with tumor grade. In mismatch-repair-deficient colorectal cancers, loss of cytoplasmic Mst1 was associated with higher $N$ stage $(P=0.019)$ and shortened survival $(P=0.0001)$. In a multivariate analysis, loss of cytoplasmic Mst1 was an independent adverse prognostic factor in this group of patients. Methylation analysis on 32 cases showed that the loss of cytoplasmic Mst1 expression is not likely due to promoter methylation. In summary, loss of cytoplasmic Mst1 expression is a marker of tumor progression in mismatchrepair-proficient as well as mismatch-repair-deficient colorectal cancers. These results are suggestive of a tumor suppressor role for Mst1 in human colorectal cancer.
\end{abstract}

Modern Pathology (2007) 20, 331-338. doi:10.1038/modpathol.3800740; published online 2 February 2007

Keywords: colorectal cancer; Mst1; prognosis; tissue microarray; immunohistochemistry; apoptosis

Mst1 (mammalian Sterile-like 1), a serine/threonine kinase, belongs to the Sterile 20-like superfamily that was originally identified as a stress-activated protein participating in a wide range of apoptotic responses. ${ }^{1,2}$ Mst1 contains an N-terminal catalytic domain and an autoinhibitory segment followed by a dimerization domain and a nuclear localization motif at the non catalytic, C-terminal part. ${ }^{3}$ Mst1 also contains a caspase-3-recognition motif, between the catalytic and regulatory domains, which mediates the cleavage of the autoinhibitory domain and yields a highly active catalytic fragment during apoptosis (Figure 1). ${ }^{4-6}$ Despite extensive studies, the mechanisms and targets through which Mst1

Correspondence: Dr P Minoo, MD, PhD, Department of Pathology, McGill University, Duff Medical Building, 3775 University Street, Montreal, QC, Canada H3A 2B4.

E-mail: parham.minoo@mcgill.ca

Received 1 September 2006; revised 31 October 2006; accepted 6 November 2006; published online 2 February 2007 regulates apoptosis are not well characterized. The pro-apoptotic function of Mst1-at least in part-is attributed to caspase-3 mediated cleavage of Mst1, although subsequent studies demonstrated that this is not essential for signaling and morphological features of apoptosis. ${ }^{7}$ In fact, Mst1 has also shown to be activated by phosphorylation of $\mathrm{Thr}^{183}$ and $\mathrm{Thr}^{187}$ in its activation loop which is promoted by dimerization. Mst1 phosphorylation results in caspase activation and apoptosis ${ }^{7,8}$ indicating that Mst1 might function both upstream and downstream of caspases. Recent findings that most Ste20 group kinases activate mitogen-activated protein kinase (MAPK) and more specifically stressed-induced p38 MAPK and JNK (c-Jun N-terminal kinase) support this model (Figure 1). ${ }^{1,8-10}$

Cellular localization of Mst1 is also regulated by caspase-mediated cleavage as well as threonine phosphorylation..$^{7,8,11}$ Under resting conditions, Mst1 is localized predominantly in the cytoplasm but cleavage of Mst1 by caspases or phosphorylation 


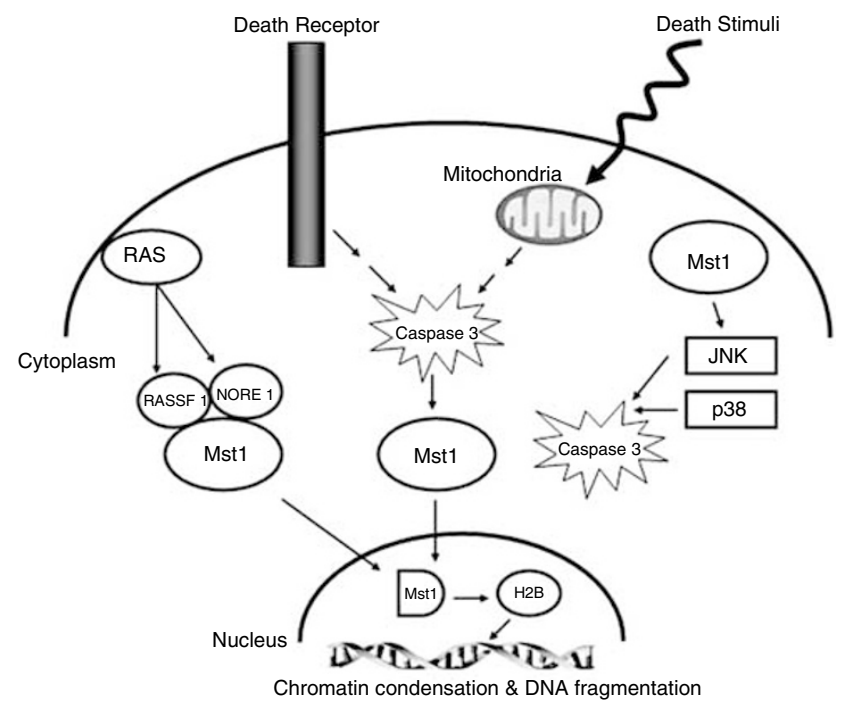

Figure 1 Schematic representation of Mst1 functions in apoptosis.

in its activation loop lead to Mst1 translocation to the nucleus. ${ }^{7,8,11}$ Nuclear retention of Mst1 results in chromatin condensation and DNA fragmentation indicating that nuclear entry of Mst1 may be important in its pro-apoptotic function. ${ }^{11,12}$ Extensive studies to identify potential Mst1 substrates in the nucleus have led to identification of Histone H2B as a physiologic substrate for the catalytic domain of Mst1, the phosphorylation of which leads to chromatin condensation and apoptosis. ${ }^{13}$

Based on its proposed function in apoptosis, Mst1 might play a tumor suppressor role in human cancers as has been suggested for its Drosophila homologs. ${ }^{14-17}$ Nevertheless, there is no report on the biological significance of Mst1 expression in primary human cancer cells. Herein, we report the prognostic significance of cytoplasmic and nuclear expression of Mst1 in a large group of patients with colorectal cancer.

\section{Materials and methods}

\section{Tissue Microarray Construction}

A tissue microarray comprising of 1420 unselected, non-consecutive colorectal cancers was constructed. ${ }^{18}$ Formalin-fixed, paraffin-embedded tissue blocks of colorectal cancer resections were retrieved from the archives of the Institute of Pathology, University Hospital of Basel, Switzerland, the Institute of Clinical Pathology, Basel, Switzerland and the Institute of Pathology, Stadtspital Triemli, Zürich, Switzerland. One tissue cylinder with a diameter of $0.6 \mathrm{~mm}$ was punched from morphologically representative tissue areas of each 'donor' tissue block and brought into one recipient paraffin block $(3 \times 2.5 \mathrm{~cm})$ using a homemade semiautomated tissue arrayer.

\section{Clinico-Pathological Parameters}

The clinico-pathologic data for 1420 patients included T stage (T1, T2, T3 and T4), N stage (N0, N1 and N2), tumor grade (G1, G2 and G3) (overall grading based on the most poorly differentiated area but excluding tumor budding at the tumor margin), vascular invasion (intramural or extramural) and survival. The distribution of these features has been described previously. ${ }^{19}$

\section{Immunohistochemistry of Tissue Microarray}

Sections $(4 \mu \mathrm{m})$ of tissue microarray blocks were transferred to an adhesive-coated slide system (Instrumedics Inc., Hackensack, NJ, USA) to facilitate the transfer of tissue sections to slides and to minimize tissue loss. Standard indirect immunoperoxidase procedures were used for IHC (Dako Envision + ). 1420 colorectal cancers and 57 normal colonic mucosa samples were immunostained for N-terminal region of Mst1 (dilution 1:200; Cell Signaling, Danvers, USA), MLH1 (clone MLH-1; dilution 1:100; BD Biosciences Pharmingen, San Jose, CA, USA), MSH2 (clone MSH-2; dilution 1:200; BD Biosciences Pharmingen, San Jose, CA, USA), MSH6 (clone 44; dilution 1:400; BD Biosciences Pharmingen, San Jose, CA, USA). After dewaxing and rehydration in $\mathrm{dH}_{2} \mathrm{O}$, sections for immunostaining were subjected to heat antigen retrieval in a microwave oven $(1200 \mathrm{~W}, 15 \mathrm{~min})$ in $1 \mathrm{mM}$ EDTA buffer pH 8.0 for Mst1, MLH1, MSH2 and in $0.01 \mathrm{~mol} / \mathrm{l}$ citrate buffer $\mathrm{pH} 6.0$ for MSH6. Endogenous peroxidase activity was blocked using $0.5 \% \mathrm{H}_{2} \mathrm{O}_{2}$. After transfer to a humidified chamber, the sections were incubated with $10 \%$ normal goat serum (Dako Cytomation) for $20 \mathrm{~min}$ and incubated with primary antibody at $4{ }^{\circ} \mathrm{C}$ overnight for hMLH1, hMSH2 and hMSH6 and Mst1. Subsequently, the sections were incubated with a peroxidase-labeled secondary antibody (K4005, EnVision + SystemHRP (AEC); DakoCytomation) for $30 \mathrm{~min}$ at room temperature. For visualization of the antigen, the sections were immersed in 3-amino-9-ethylcarbazole + substrate-chromogen (K4005, EnVision + System-HRP (AEC); DakoCytomation) for $30 \mathrm{~min}$, and counterstained lightly with Gill's haematoxylin (Figure 2).

\section{Evaluation of Immunohistochemistry}

Cytoplasmic and nuclear Mst1 immunoreactivity were separately evaluated semi-quantitatively using $\%$-positivity defined as the proportion of Mst1 positive tumor cells over the total number of tumor cells ranging from 0 to $100 \%$. Scores were based on $5 \%$ intervals $(0,5,10 \%$, etc). The 1420 colorectal cancers were scored by one experienced surgical pathologist (AL) blinded to the clinicopathological features. MLH1, MSH2 and MSH6 were 

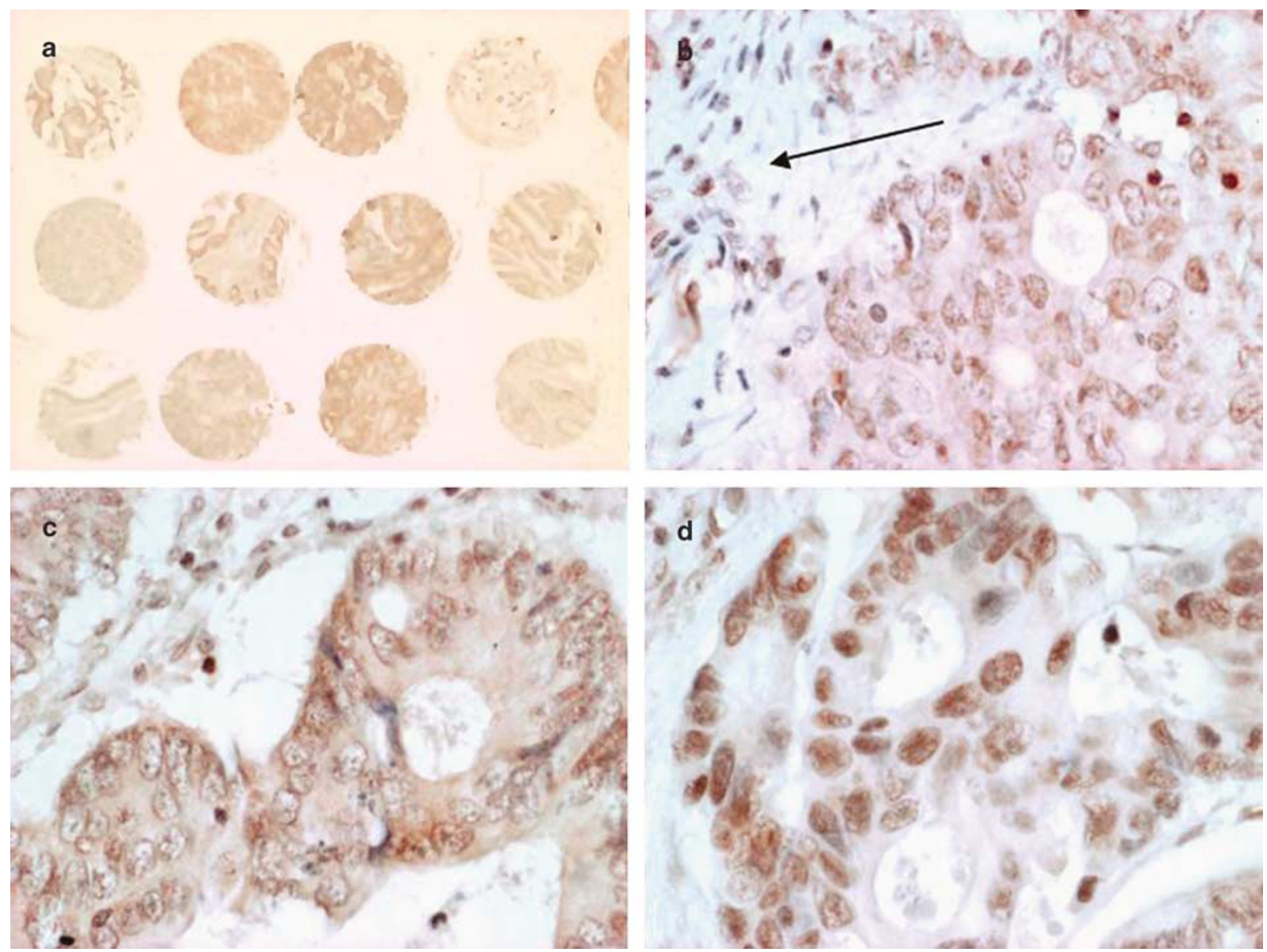

Figure 2 Different colorectal cancer punches showing varying positivity of Mst1 staining (a) $(\times 2)$. Predominantly cytoplasmic Mst1 expression in two moderately differentiated MMR-proficient colorectal cancer (arrow: negative stroma with few scattered Mst1 positive inflammatory cells) $(\mathbf{b}, \mathbf{c})(\times 40)$. Nuclear Mst1 expression in a moderately differentiated MMR-proficient colon cancer $(\mathbf{d})(\times 40)$.

scored as negative ( $0 \%$ staining) or positive $(>0 \%$ staining).

\section{Mismatch-Repair Status}

The 1420 colorectal cancers were stratified according to DNA mismatch-repair (MMR) status and consisted of 1197 MMR-proficient tumors expressing MLH1, MSH2 and MSH6, 141 MLH1-negative tumors, and 82 presumed HNPCC cases demonstrating loss of MSH2 and/or MSH6 at any age $(N=73)$, or loss of MLH1 at $<55$ years $(N=9) .{ }^{20}$ Only the MMR-proficient tumors were randomized into two matched groups in view of the large number of available cases $(N=1197,84.4 \%)$.

\section{Randomization of MMR-Proficient Colorectal Cancers}

The 1197 MMR-proficient colorectal cancers were randomly assigned into two subgroups, study group $1(N=599)$ and study group $2(N=598)$ (Table 1$)$. Study group 1 served to determine the most relevant cutoffs of cytoplasmic and nuclear Mst1 positivity and the clinico-pathologic features. The associations of Mst1 expression at the proposed cutoffs with T stage, $\mathrm{N}$ stage, tumor grade, vascular invasion and survival were investigated on study group 2 as well as in the third group containing 141 cases with MLH1-negative tumors.

\section{DNA Extraction and Bisulphite Modification}

Samples were micro-dissected from paraffin-embedded tissue using two 8-micron-thick sections. Cell lysis and DNA extraction were performed using a QIAamp DNA mini kit (QIAGEN, Mississauga, ON, Canada) according to manufacturer's protocol. Extracted genomic DNA was diluted in $40 \mu \mathrm{l}$ of distilled water and denatured by adding $6 \mu \mathrm{l}$ of $2 \mathrm{~N}$ $\mathrm{NaOH}$ and incubation at $75^{\circ} \mathrm{C}$ for $20 \mathrm{~min}$. $500 \mu \mathrm{l}$ of freshly prepared $4.8 \mathrm{M}$ sodium bisulphite and $28 \mu \mathrm{l}$ of $10 \mathrm{mM}$ hydroquinone were added to the denatured genomic DNA and the reaction was carried out overnight in dark at $55^{\circ} \mathrm{C}$. DNA then was purified using a Wizard DNA clean-up (Promega, Madison, WI, USA) and then ethanol-precipitated after $5 \mathrm{~min}$ 
Table 1 Characteristics of the randomized MMR-proficient subgroups

\begin{tabular}{|c|c|c|c|}
\hline & $\begin{array}{l}\text { Group } 1 \\
(\mathrm{~N}=599)\end{array}$ & $\begin{array}{l}\text { Group } 2 \\
(\mathrm{~N}=598)\end{array}$ & $\mathrm{P}$-value $\mathrm{a}^{\mathrm{a}}$ \\
\hline \multicolumn{4}{|l|}{ Sex } \\
\hline Male & $288(48.3)$ & $287(48.2)$ & \multirow[t]{2}{*}{0.235} \\
\hline Female & $308(51.7)$ & $308(51.8)$ & \\
\hline \multicolumn{4}{|l|}{ Tumor location } \\
\hline Right-sided & 417 (70.6) & 417 (71.2) & \multirow[t]{2}{*}{0.82} \\
\hline Left-sided & $174(29.4)$ & $169(28.8)$ & \\
\hline \multicolumn{4}{|l|}{ T stage } \\
\hline $\mathrm{T} 1$ & $25(4.3)$ & $35(6.0)$ & \multirow{4}{*}{0.514} \\
\hline $\mathrm{T} 2$ & $92(15.8)$ & 97 (16.7) & \\
\hline T3 & $375(64.2)$ & $365(62.8)$ & \\
\hline $\mathrm{T} 4$ & $92(15.8)$ & $84(14.5)$ & \\
\hline \multicolumn{4}{|l|}{$N$ stage } \\
\hline No & $289(50.7)$ & $298(52.1)$ & \multirow[t]{3}{*}{0.847} \\
\hline N1 & $154(27.0)$ & $154(26.9)$ & \\
\hline $\mathrm{N} 2$ & $127(22.3)$ & $120(21.0)$ & \\
\hline \multicolumn{4}{|l|}{ Tumor grade } \\
\hline G1 & $14(2.4)$ & $13(2.2)$ & \multirow[t]{3}{*}{0.969} \\
\hline G2 & 503 (86.7) & 507 (86.7) & \\
\hline G3 & $63(10.9)$ & $65(11.1)$ & \\
\hline \multicolumn{4}{|l|}{ Vascular invasion } \\
\hline Presence & $169(29.1)$ & $163(27.9)$ & \multirow[t]{2}{*}{0.643} \\
\hline Absence & $412(70.9)$ & $422(72.1)$ & \\
\hline $\begin{array}{l}\text { Survival median } \\
(95 \% \text { CI })\end{array}$ & $\begin{array}{c}68.0 \\
(57.0-91.0)\end{array}$ & $\begin{array}{c}76.0 \\
(62.0-88.0)\end{array}$ & 0.59 \\
\hline
\end{tabular}

${ }^{\mathrm{a}} \chi^{2}$ Test for sex, tumor location, $\mathrm{T}$ stage, $\mathrm{N}$ stage, tumor grade and vascular invasion, log-rank test for survival analysis.

$P>0.05$ indicate that there is no difference between groups 1 and 2 .

of alkali treatment with $8.8 \mu \mathrm{l}$ of $2 \mathrm{~N} \mathrm{NaOH}$ at room temperature.

\section{Methylation of Mst1}

Methylation of Mst1 promoter was examined by methylation-specific PCR (MSP) using AmpliTaq Gold kit (Roche, Branchburg, NJ, USA) as described previously. ${ }^{21}$ The primers for amplification of unmethylated sequence were 5'-TTTTGGTAATG TAGGAAGATAGTGT- $3^{\prime}$ and $3^{\prime}$-AAACCACAACCC TAATCACATA-5' and primer sequences for methylated reaction were $5^{\prime}$-GTTTCGGTAACGTAGGAA GATAGC- $3^{\prime}$ and $3^{\prime}$-AACCACGACCCTAATCACGTA$5^{\prime}$. The condition for amplification was $10 \mathrm{~min}$ at $95^{\circ} \mathrm{C}$ followed by 39 cycles of denaturing at $95^{\circ} \mathrm{C}$ for $30 \mathrm{~s}$, annealing at $56^{\circ} \mathrm{C}$ for $30 \mathrm{~s}$ and $30 \mathrm{~s}$ of extension at $72^{\circ} \mathrm{C}$. PCR products were subjected to electrophoresis on $8 \%$ acrylamide gels and visualized by SYBR gold nucleic acid gel stain (Molecular Probes, Eugene, USA). CpGenome Universal Methylated DNA (Chemicon, Temecula, CA, USA) was used as a positive control for methylation.

\section{Statistical Analysis}

The selection of clinically important cutoff scores for Mst1 expression was based on receiver operating characteristic (ROC) curve analysis. ${ }^{22}$ At each percentage score, the sensitivity and specificity for the outcome under study was plotted, thus generating a ROC curve. The score having the shortest distance to the point with both maximum sensitivity and specificity, that is, the point $(0.0,1.0)$ on the curve, and thereby minimizing the trade-off between the two, was selected as the cutoff score. Categorizing tumors as positive or negative around this score leads to the greatest number of tumors correctly classified as having or not having the clinical outcome. The reliability of the selected cutoff scores was determined by 1000-bootstrapped replications to re-sample the data. With bootstrapping, 1000 re-samples of equal size were created. ROC curve analysis was performed for each sub-group and a cutoff score was obtained. The most frequently obtained score over the 1000 re-samples was selected as the cutoff score for Mst1 positivity. In order to use ROC curve analysis, the clinicopathological features were dichotomized: $\mathrm{T}$ stage (early (T1 + T2) or late (T3+ T4)), N stage (No (no lymph node involvement) or $>$ No (any lymph node involvement)), tumor grade (low (G1 + G2) or high (G3)), vascular invasion (absent or present), and survival (death due to colorectal cancer or censored (lost to follow-up, alive or death from other causes)).

The association of cytoplasmic and nuclear Mst1 (retention/loss) and T stage, $\mathrm{N}$ stage, tumor grade and vascular invasion were evaluated at their respective cutoffs using the $\chi^{2}$ test. Univariate survival analysis was carried out using the Kaplan-Meier method, and by Cox proportional hazards regression. Multivariate survival analysis was performed by including $\mathrm{T}$ stage, $\mathrm{N}$ stage, tumor grade, vascular invasion and Mst1 expression. All analyses were carried out using SAS, version 9 (The SAS Institute, Cary, NC, USA).

\section{Results}

\section{Normal Colonic Mucosa}

In normal colonic mucosa Mst1 immunoreactivity regardless of the extent occurred in $73.7 \%$ of cases.

\section{Cytoplasmic Mst1 in MMR-Proficient Colorectal Cancer (Table 2)}

The optimum cutoff for loss of cytoplasmic Mst1 was $<80 \%$ for all clinico-pathological parameters. In a $\chi^{2}$ test, loss of cytoplasmic Mst1 was observed more frequently in tumor stages T3 and T4, while retention of cytoplasmic Mst1 was associated with early (T1 and T2) tumor stages $(P=0.001)$ (Table 2). Additionally there was an association between loss of cytoplasmic Mst1 and presence of lymph node 
Table 2 Association of clinico-pathological features and cytoplasmic Mst1 retention $(>80 \%)$ and loss $(\leq 80 \%)$ in MMRproficient colorectal cancer (study group 2)

\begin{tabular}{|c|c|c|c|c|c|}
\hline & \multicolumn{2}{|c|}{ Loss } & \multicolumn{2}{|c|}{ Retention } & \multirow[t]{2}{*}{$\mathrm{P}$-value } \\
\hline & $\mathrm{N}$ & $(\%)$ & $\mathrm{N}$ & $(\%)$ & \\
\hline \multicolumn{6}{|l|}{ T stage } \\
\hline $\mathrm{T} 1$ & 4 & $(2.7)$ & 20 & (6.1) & \multirow{4}{*}{0.001} \\
\hline $\mathrm{T} 2$ & 13 & $(8.8)$ & 68 & (21.1) & \\
\hline T3 & 103 & (70.1) & 198 & (61.3) & \\
\hline $\mathrm{T} 4$ & 27 & (18.3) & 37 & (11.5) & \\
\hline \multicolumn{6}{|l|}{$N$ stage } \\
\hline No & 66 & $(44.0)$ & 172 & $(54.8)$ & \multirow[t]{2}{*}{0.029} \\
\hline $\mathrm{N} 1+\mathrm{N} 2$ & 84 & (56.0) & 142 & $(45.2)$ & \\
\hline \multicolumn{6}{|l|}{ Tumor grade } \\
\hline $\mathrm{G} 1+\mathrm{G} 2$ & 131 & $(87.9)$ & 298 & (91.7) & \multirow[t]{2}{*}{0.193} \\
\hline G3 & 18 & (12.1) & 27 & $(8.31)$ & \\
\hline \multicolumn{6}{|c|}{ Vascular invasion } \\
\hline Presence & 54 & $(36.2)$ & 83 & $(25.5)$ & \multirow{2}{*}{0.017} \\
\hline Absence & 95 & (63.8) & 242 & $(74.5)$ & \\
\hline $\begin{array}{l}\text { Survival time } \\
\text { median (95\% } \\
\text { CI) (months) }\end{array}$ & \multicolumn{2}{|c|}{$\begin{array}{c}52.0 \\
(34.0-82.0)\end{array}$} & \multicolumn{2}{|c|}{$\begin{array}{c}81.0 \\
(62.0-113.0)\end{array}$} & 0.014 \\
\hline
\end{tabular}

${ }^{\mathrm{a}} \chi^{2}$ Test for T stage, $\mathrm{N}$ stage, tumor grade and vascular invasion, logrank test for univariate survival analysis.

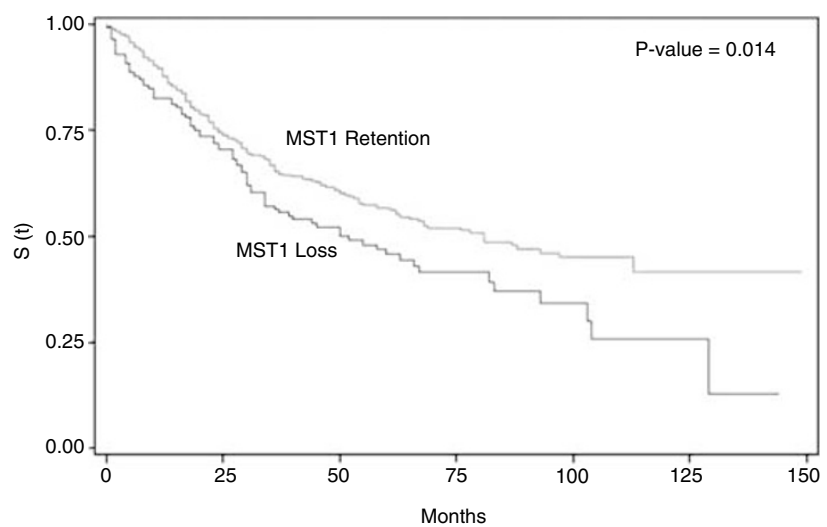

Figure 3 Overall survival curves for MMR-proficient colorectal cancers with retention or loss of cytoplasmic Mst1.

metastasis $(P=0.029)$, vascular invasion $(P=0.017)$ and worse survival $(P=0.014)$ (Mst1 retention: 81.0 months; Mst1 loss: 52.0 months) (Figure 3).

\section{Nuclear Mst1 in MMR-Proficient Colorectal Cancer (Table 3)}

The optimum cutoffs for nuclear Mst1 as determined on subgroup 1 differed for the various endpoints: $50 \%$ for $\mathrm{T}$ stage, $40 \%$ for $\mathrm{N}$ stage and vascular invasion, $70 \%$ for tumor grade and $30 \%$ for overall survival. In a univariate analysis nuclear
Table 3 Association of clinico-pathological features and nuclear Mst1 expression ( $\geq$ cutoff) and loss (<cutoff) in MMR-proficient colorectal cancer (study group 2)

\begin{tabular}{|c|c|c|c|c|c|c|}
\hline & \multirow{2}{*}{$\begin{array}{c}\text { Cutoff } \\
(\%)\end{array}$} & \multicolumn{2}{|c|}{ Loss } & \multicolumn{2}{|c|}{ Expression } & \multirow[t]{2}{*}{$\mathrm{P}$-value } \\
\hline & & $\mathrm{N}$ & $(\%)$ & $\mathrm{N}$ & $(\%)$ & \\
\hline T stage & 50 & & & & & \\
\hline $\mathrm{T} 1$ & & 14 & (5.5) & 10 & $(4.6)$ & 0.242 \\
\hline $\mathrm{T} 2$ & & 37 & (14.6) & 44 & (20.3) & \\
\hline T3 & & 171 & (67.6) & 130 & (59.9) & \\
\hline $\mathrm{T} 4$ & & 31 & (12.3) & 33 & (15.2) & \\
\hline$N$ stage & 40 & & & & & \\
\hline No & & 112 & (53.9) & 126 & (49.2) & 0.321 \\
\hline $\mathrm{N} 1+\mathrm{N} 2$ & & 96 & $(46.2)$ & 130 & $(50.8)$ & \\
\hline Tumor grade & 70 & & & & & \\
\hline $\mathrm{G} 1+\mathrm{G} 2$ & & 326 & $(94.2)$ & 103 & (80.5) & $<0.001$ \\
\hline G3 & & 20 & $(5.8)$ & 25 & (19.5) & \\
\hline $\begin{array}{l}\text { Vascular } \\
\text { invasion }\end{array}$ & 40 & & & & & \\
\hline Presence & & 59 & (27.6) & 78 & (30.0) & 0.561 \\
\hline Absence & & 155 & $(72.4)$ & 182 & (70.0) & \\
\hline $\begin{array}{l}\text { Survival time } \\
\text { median (95\% } \\
\text { CI) (months) }\end{array}$ & 30 & $\begin{array}{r}8 \\
(61.0-\end{array}$ & $\begin{array}{l}.0 \\
113.0)\end{array}$ & (46. & $\begin{array}{l}.0 \\
-81.0)\end{array}$ & 0.275 \\
\hline
\end{tabular}

${ }^{\mathrm{a}} \chi^{2}$ Test for $\mathrm{T}$ stage, $\mathrm{N}$ stage, tumor grade and vascular invasion, logrank test for univariate survival analysis.

Mst1 expression was not significantly associated with $\mathrm{N}$ stage, $\mathrm{T}$ stage or vascular invasion.

\section{Cytoplasmic Mst1 in MMR-Deficient Colorectal Cancer (Table 4)}

The optimum cutoff for cytoplasmic Mst1 was also found to be $80 \%$ for all clinico-pathological parameters. In a univariate analysis, loss of cytoplasmic Mst1 was associated with the presence of lymph node metastasis $(P=0.019)$ and worse survival $(P=0.0001)$ (Mst1 retention: 74.1 months; Mst1 loss: 31.7 months) (Figure 4).

\section{Multivariate Analysis of Survival}

In a multivariate analysis, which included T stage, $\mathrm{N}$ stage, tumor grade, vascular invasion and age, loss of cytoplasmic Mst1 was not an independent prognostic factor in MMR-proficient colorectal cancers $(P=0.679)$. However, multivariate analysis using the same criteria demonstrated that loss of cytoplasmic Mst1 was an independent adverse prognostic factor in MMR-deficient colorectal cancers $(P=0.03)$.

\section{Methylation Analysis of Mst1 Promoter}

In order to investigate whether loss of Mst1 expression is a result of promoter methylation, we carried 
Table 4 Association of clinico-pathological features and cytoplasmic Mst1 expression ( $\geq 80 \%$ cutoff) and loss ( $<80 \%$ cutoff) in MMR-deficient colorectal cancer (study group 3)

\begin{tabular}{|c|c|c|c|c|c|}
\hline & \multicolumn{2}{|c|}{ Loss } & \multicolumn{2}{|c|}{ Retention } & \multirow[t]{2}{*}{$\mathrm{P}$-value } \\
\hline & $\mathrm{N}$ & $(\%)$ & $\mathrm{N}$ & $(\%)$ & \\
\hline \multicolumn{6}{|l|}{ T stage } \\
\hline $\mathrm{T} 1$ & 0 & $(0.0)$ & 0 & $(0.0)$ & \multirow{4}{*}{0.381} \\
\hline $\mathrm{T} 2$ & 1 & $(2.1)$ & 5 & $(6.7)$ & \\
\hline T3 & 34 & $(70.8)$ & 55 & (73.3) & \\
\hline $\mathrm{T} 4$ & 13 & $(27.1)$ & 15 & $(20.0)$ & \\
\hline \multicolumn{6}{|l|}{$N$ stage } \\
\hline No & 22 & $(44.9)$ & 49 & $(66.2)$ & \multirow[t]{2}{*}{0.019} \\
\hline $\mathrm{N} 1+\mathrm{N} 2$ & 27 & (55.1) & 25 & (33.8) & \\
\hline \multicolumn{6}{|l|}{ Tumor grade } \\
\hline $\mathrm{G} 1+\mathrm{G} 2$ & 33 & (68.8) & 61 & (81.3) & \multirow[t]{2}{*}{0.1088} \\
\hline G3 & 15 & $(31.2)$ & 14 & (18.7) & \\
\hline \multicolumn{6}{|c|}{ Vascular invasion } \\
\hline Presence & 17 & (35.4) & 15 & (20.3) & \multirow[t]{2}{*}{0.063} \\
\hline Absence & 31 & (64.6) & 59 & $(79.7)$ & \\
\hline $\begin{array}{l}\text { Survival time } \\
\text { mean } \pm \text { s.e. }\end{array}$ & \multicolumn{2}{|c|}{$31.7 \pm 3.9$} & \multicolumn{2}{|c|}{$74.1 \pm 4.1$} & $<0.0001$ \\
\hline
\end{tabular}

${ }^{\mathrm{a}} \chi^{2}$ Test for $\mathrm{T}$ stage, $\mathrm{N}$ stage, tumor grade and vascular invasion, log-rank test for univariate survival analysis.

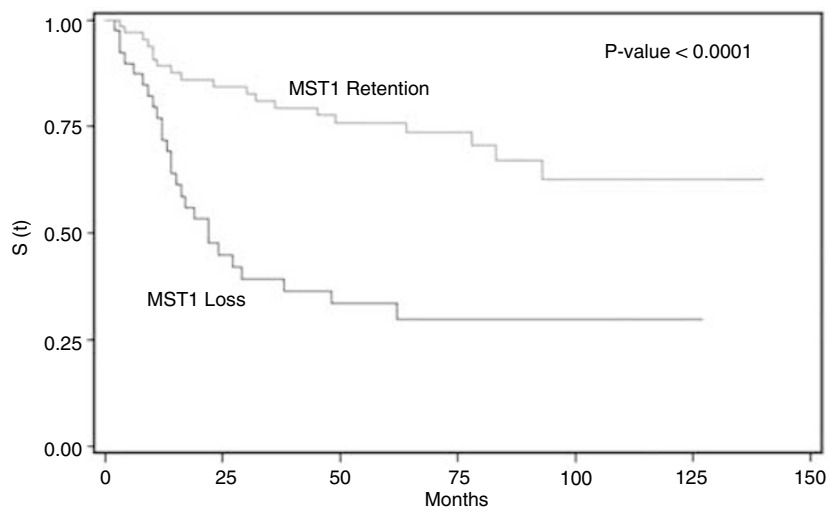

Figure 4 Overall survival curves for MMR-deficient colorectal cancers with retention or loss of cytoplasmic Mst1.

out MSP studies on 16 cases with near complete or complete loss of Mst1 expression in MLH1 proficient group and 16 cases in MLH1 negative group. The results showed no methylation in the selected promoter region of Mst1 in both groups (data not shown).

\section{Discussion}

In this study, we analyzed the prognostic value of Mst1 expression in 1197 MMR-proficient as well as 141 MMR-deficient colorectal cancers using tissue microarray technology and immunohistochemistry. The tissue microarray technique is an accepted tool of investigation, especially when a huge number of samples are analyzed. ${ }^{18,23-28}$ The randomization of the study population into two subgroups allowed us to determine the best cutoffs for cytoplasmic and nuclear Mst1 expression on the first subgroup $(N=599)$ based on the ROC curve analysis and to apply the determined cutoffs on the second subgroup $(N=598)$ as well as on the third group $(N=141)$. This approach has the important advantage of avoiding a scoring system that includes a subjectively selected cutoff or a complex composite scoring system. Indeed, the different cutoffs for nuclear Mst1 dependent on the clinico-pathological parameter analyzed clearly underlines the importance of ROC curve analysis in the immunohistochemical analysis of potential tumor markers.

In normal colon mucosa Mst1 was found predominantly in the cytoplasm but there was nuclear staining to a lesser extent. This is consistent with the finding that endogenous Mst1 accumulates in the nucleus upon treatment with leptomycin Ba specific inhibitor of nuclear export-suggesting that Mst1 shuttles continuously between cytoplasm and nucleus. ${ }^{7,29}$

Univariate analysis in the MMR-proficient group showed that loss of cytoplasmic Mst1 was associated with higher $\mathrm{T}$ and $\mathrm{N}$ stages, vascular invasion and worse survival. These results are consistent with Mst1 function in induction of apoptosis and tumor suppression. Patients with MMR-proficient colorectal cancers are more likely to have $A P C$, $K R A S$, and P53 mutations and are microsatellite stable (MSS). ${ }^{30}$ There has been increasing evidence that Ras and other oncogenes paradoxically induce both pro- and anti-apoptotic signaling. ${ }^{31,32}$ NORE1 and RASSF1 are two members of the RASSF family known to have putative RAS-binding domains and mediate RAS-induced apoptotic signals. ${ }^{33-35}$ Further studies demonstrated that these two proteins are binding partners of Mst1 and their complex formation with Mst1 is critical to the mechanism of RAS-induced apoptosis (Figure 1). ${ }^{36,37}$ Loss of Mst1 expression will change the balance of RAS-induced contradictory signals in favor of anti-apoptotic ones and provide a further explanation for the association of clinico-pathological outcomes and Mst1 expression in MMR proficient colorectal cancers.

Based on the proposed mechanism of Mst1 in induction of apoptosis (see introductory text) we expected to observe an association between the loss of Mst1 nuclear expression with worse clinicopathological outcomes. However, in our analysis, Mst1 nuclear expression did not show a significant association with tumor stage, vascular invasion or survival. As nuclear localization of Mst1 is promoted by caspase-mediated cleavage and threonine phosphorylation, it is conceivable that these two modifications interfere with antigen/antibody complexing in immunohistochemistry. 
In the MMR-deficient group, we found that $80 \%$ was also the best cutoff for different clinicopathological variables. Univariate analysis in this group showed that the loss of cytoplasmic Mst1 is associated with lymph node metastasis and worse survival. These results firstly confirm the role of Mst1 as a tumor suppressor gene and secondly indicate that the $80 \%$ cutoff for cytoplasmic expression of Mst1 is a valid and useful criterion in prediction of clinico-pathologic features of a tumor. Loss of MLH1 expression is highly deleterious and results in apoptosis due to the rapid accumulation of DNA mismatch errors. Thus, loss of MLH1 expression is only tolerated when the mechanisms leading to apoptosis are extensively disrupted. In fact, inhibition of apoptosis has been regarded as a central pathogenic mechanism in development of serrated polyps which are the likely precursors of sporadic MSI-H colorectal cancers. ${ }^{38,39}$ This might explain why in the multivariate analysis, loss of cytoplasmic Mst1 showed a significant effect on survival only in the MLH1-negative group.

CpG island methylation is an epigenetic mechanism commonly involved in silencing of gene transcription leading to development of cancer. ${ }^{40}$ Methylation in the promoter region of Mst1 has been reported in normal colon mucosa in patients with hyperplastic polyposis. ${ }^{21}$ Our methylation analysis showed that methylation of gene promoter is not a likely mechanism for explaining Mst1 loss of expression in MMR proficient and MMR deficient colorectal cancers. Hence, we suggest the presence of other mechanisms, (eg mutation, loss of heterozygosity) may be responsible for downregulation of Mst1 expression in colorectal cancers.

In summary, the results of this study indicate that loss of cytoplasmic Mst1 is associated with higher T and/or $\mathrm{N}$ stage, higher tumor grade and poor prognosis in colorectal cancer patients, suggesting a tumor suppressor role for Mst1 in human colorectal cancer.

\section{Acknowledgements}

This study was supported by a grant from the Swiss National Foundation (Grant no. PBBSB-110417) and the Novartis Foundation, formerly Ciba-Geigy-Jubilee-Foundation. We thank Privatdozent Dr Hanspeter Spichtin, Institute of Clinical Pathology Basel, Switzerland and Professor Dr Robert Maurer, Institute of Pathology, Stadtspital Triemli, Zuerich, Switzerland for providing the cases.

\section{References}

1 Creasy CL, Chernoff J. Cloning and characterization of a member of the MST subfamily of Ste20-like kinases. Gene 1995;167:303-306.
2 Taylor LK, Wang HC, Erikson RL. Newly identified stress-responsive protein kinases, Krs-1 and Krs-2. Proc Natl Acad Sci USA 1996;93:10099-10104.

3 Creasy CL, Ambrose DM, Chernoff J. The Ste20-like protein kinase, Mst1, dimerizes and contains an inhibitory domain. J Biol Chem 1996;271:21049-21053.

4 Reszka AA, Halasy-Nagy JM, Masarachia PJ, et al. Bisphosphonates act directly on the osteoclast to induce caspase cleavage of mst1 kinase during apoptosis. A link between inhibition of the mevalonate pathway and regulation of an apoptosis-promoting kinase. J Biol Chem 1999;274:34967-34973.

5 Lee KK, Murakawa M, Nishida E, et al. Proteolytic activation of MST/Krs, STE20-related protein kinase, by caspase during apoptosis. Oncogene 1998;16: 3029-3037.

6 Kakeya H, Onose R, Osada H. Caspase-mediated activation of a $36-\mathrm{kDa}$ myelin basic protein kinase during anticancer drug-induced apoptosis. Cancer Res 1998;58:4888-4894.

7 Lee KK, Yonehara S. Phosphorylation and dimerization regulate nucleocytoplasmic shuttling of mammalian STE20-like kinase (MST). J Biol Chem 2002;277: 12351-12358.

8 Glantschnig H, Rodan GA, Reszka AA. Mapping of MST1 kinase sites of phosphorylation. Activation and autophosphorylation. J Biol Chem 2002;277: 42987-42996.

9 Graves JD, Gotoh Y, Draves KE, et al. Caspase-mediated activation and induction of apoptosis by the mammalian Ste20-like kinase Mst1. EMBO J 1998;17:2224-2234.

10 Ura S, Masuyama N, Graves JD, et al. MST1-JNK promotes apoptosis via caspase-dependent and independent pathways. Genes Cells 2001;6:519-530.

11 Lee KK, Ohyama T, Yajima N, et al. MST, a physiological caspase substrate, highly sensitizes apoptosis both upstream and downstream of caspase activation. J Biol Chem 2001;276:19276-19285.

12 Ura S, Masuyama N, Graves JD, et al. Caspase cleavage of MST1 promotes nuclear translocation and chromatin condensation. Proc Natl Acad Sci USA 2001;98: 10148-10153.

13 Cheung WL, Ajiro K, Samejima K, et al. Apoptotic phosphorylation of histone $\mathrm{H} 2 \mathrm{~B}$ is mediated by mammalian sterile twenty kinase. Cell 2003;113: 507-517.

$14 \mathrm{Wu}$ S, Huang J, Dong J, et al. hippo encodes a Ste-20 family protein kinase that restricts cell proliferation and promotes apoptosis in conjunction with salvador and warts. Cell 2003;114:445-456.

15 Jia J, Zhang W, Wang B, et al. The Drosophila Ste20 family kinase dMST functions as a tumor suppressor by restricting cell proliferation and promoting apoptosis. Genes Dev 2003;17:2514-2519.

16 Harvey KF, Pfleger CM, Hariharan IK. The Drosophila Mst ortholog, hippo, restricts growth and cell proliferation and promotes apoptosis. Cell 2003;114: 457-467.

17 Pantalacci S, Tapon N, Leopold P. The Salvador partner Hippo promotes apoptosis and cell-cycle exit in Drosophila. Nat Cell Biol 2003;5:921-927.

18 Sauter G, Simon R, Hillan K. Tissue microarrays in drug discovery. Nat Rev Drug Discov 2003;2:962-972.

19 Lugli A, Zlobec I, Gunthert U, et al. Overexpression of the receptor for hyaluronic acid mediated motility is an independent adverse prognostic factor in colorectal cancer. Mod Pathol 2006;19:1302-1309. 
20 Hampel H, Frankel WL, Martin E, et al. Screening for the Lynch syndrome (hereditary nonpolyposis colorectal cancer). N Engl J Med 2005;352:1851-1860.

21 Minoo P, Baker K, Goswami R, et al. Extensive DNA methylation in normal colorectal mucosa in hyperplastic polyposis. Gut 2006;55:1467-1474.

22 Hanley JA. Receiver operating characteristic (ROC) methodology: the state of the art. Crit Rev Diagn Imaging 1989;29:307-335.

23 Moch H, Schraml P, Bubendorf L, et al. Highthroughput tissue microarray analysis to evaluate genes uncovered by cDNA microarray screening in renal cell carcinoma. Am J Pathol 1999;154:981-986.

24 Nocito A, Bubendorf L, Tinner EM, et al. Microarrays of bladder cancer tissue are highly representative of proliferation index and histological grade. J Pathol 2001;194:349-357.

25 Simon R, Nocito A, Hubscher T, et al. Patterns of her-2/ neu amplification and overexpression in primary and metastatic breast cancer. J Natl Cancer Inst 2001;93: 1141-1146.

26 Torhorst J, Bucher C, Kononen J, et al. Tissue microarrays for rapid linking of molecular changes to clinical endpoints. Am J Pathol 2001;159:2249-2256.

27 Goethals L, Perneel C, Debucquoy A, et al. A new approach to the validation of tissue microarrays. J Pathol 2006;208:607-614.

28 Barlund M, Forozan F, Kononen J, et al. Detecting activation of ribosomal protein S6 kinase by complementary DNA and tissue microarray analysis. J Natl Cancer Inst 2000;92:1252-1259.

29 Lin Y, Khokhlatchev A, Figeys D, et al. Death-associated protein 4 binds MST1 and augments MST1-induced apoptosis. J Biol Chem 2002;277:47991-48001.

30 Vogelstein B, Fearon ER, Hamilton SR, et al. Genetic alterations during colorectal-tumor development. N Engl J Med 1988;319:525-532.
31 Cox AD, Der CJ. The dark side of Ras: regulation of apoptosis. Oncogene 2003;22:8999-9006.

32 Feig LA, Buchsbaum RJ. Cell signaling: life or death decisions of ras proteins. Curr Biol 2002;12: R259-R261.

33 Vavvas D, Li X, Avruch J, et al. Identification of Nore1 as a potential Ras effector. J Biol Chem 1998;273: 5439-5442.

34 Dammann R, Li C, Yoon JH, et al. Epigenetic inactivation of a RAS association domain family protein from the lung tumour suppressor locus 3p21.3. Nat Genet 2000;25:315-319.

35 Lerman MI, Minna JD. The 630-kb lung cancer homozygous deletion region on human chromosome 3p21.3: identification and evaluation of the resident candidate tumor suppressor genes. The International Lung Cancer Chromosome 3p21.3 Tumor Suppressor Gene Consortium. Cancer Res 2000;60: 6116-6133.

36 Khokhlatchev A, Rabizadeh S, Xavier $\mathrm{R}$, et al. Identification of a novel Ras-regulated proapoptotic pathway. Curr Biol 2002;12:253-265.

37 Praskova M, Khoklatchev A, Ortiz-Vega S, et al. Regulation of the MST1 kinase by autophosphorylation, by the growth inhibitory proteins, RASSF1 and NORE1, and by Ras. Biochem J 2004;381:453-462.

38 Tateyama H, Li W, Takahashi E, et al. Apoptosis index and apoptosis-related antigen expression in serrated adenoma of the colorectum: the saw-toothed structure may be related to inhibition of apoptosis. Am J Surg Pathol 2002;26:249-256.

39 Jass JR, Whitehall VL, Young J, et al. Emerging concepts in colorectal neoplasia. Gastroenterology 2002;123:862-876.

40 Herman JG, Baylin SB. Gene silencing in cancer in association with promoter hypermethylation. N Engl J Med 2003;349:2042-2054. 